\title{
CAFÉ DE ESPECIALIDAD: ALTERNATIVA PARA EL SECTOR CAFETALERO PERUANO*
}

\author{
Pilar Castro \\ Yabed Contreras \\ Delia Laca \\ Keiko Nakamatsu \\ GRADUANDOS DE ESAN \\ PROGRAMA MAGÍSTER EN ADMINISTRACIÓN \\ esanediciones@esan.edu.pe
}

\section{Resumen}

Si bien el café en general es un commodity, en los últimos años se ha identificado un nicho de mercado rentable: el del café de especialidad. Para acceder a este mercado, el café debe ser de la más alta calidad, ser producido en microclimas geográficos específicos, tener un sabor particular y ser extraído siguiendo estándares rigurosamente establecidos. El Perú cuenta con ventajas comparativas para obtener café de especialidad porque tiene una de las mejores variedades botánicas de café, condiciones climáticas y geográficas adecuadas y disponibilidad de agua en zonas tropicales de altura. Sin embargo, para lograr competitividad es necesario superar limitaciones en cuanto a recursos, tecnología, organización y gestión, así como formular estrategias de largo plazo en las que se consideren los intereses de toda la cadena productiva, desde los agricultores hasta los exportadores, en una relación de "ganar-ganar» basada en el conocimiento profundo de la realidad actual del sector y del mercado internacional.

C uando en 1989 la Organización Internacional del Café (OIC) eliminó el sistema de cuotas anuales de exportación de café en grano verde establecido aproximadamente veinte años antes, los precios internacionales del café sufrieron

* Investigación de base utilizada en la tesis que los autores están elaborando para optar el grado de magíster en Administración Internacional de ESAN. Ellos quieren dejar constancia una estrepitosa caída por el rápido aumento de la oferta proveniente de las cuantiosas reservas de los países productores (International Coffee Organization, 2004). Desde entonces los productores de café viven una crisis de la cual no han podido

de su reconocimiento a sus asesores, los profesores Octavio Chirinos y Eduardo McBride, por sus valiosos comentarios y sugerencias. 
recuperarse. La reacción de la mayoría de ellos frente a la tendencia a la baja de los precios ha sido concentrarse en incrementar los volúmenes de producción, con lo cual han llegado a descuidar la calidad del grano. La baja calidad sumada a la excesiva oferta ha ocasionado cada vez menores precios y generado un círculo vicioso, lo que ha sumido en la pobreza a millones de caficultores en todo el mundo.

En este contexto, emerge contra la corriente el mercado de café de especialidad como un nicho que paga precios elevados y presenta altas tasas de crecimiento. Se denomina café de especialidad a aquel que reúne ciertas características: la más alta calidad, un sabor particular y el cultivo en microclimas geográficos específicos siguiendo estándares rigurosamente establecidos. Algunos países, como Costa Rica, han encontrado en este nicho una alternativa prometedora para superar la crisis de precios y desarrollan estrategias nacionales con el fin de orientar todo su sector cafetalero hacia este nicho. El caso peruano ratifica también lo ventajoso de esta alternativa (ver nota de prensa en la página siguiente).

El Perú incursionó en el café de especialidad a partir de 1992; desde entonces sus exportaciones de este producto han crecido en forma exponencial. Según la Junta Nacional del Café (JNC) y otras fuentes oficiales, en el año 2002 alcanzaron los 355 mil quintales y generaron un ingreso aproximado de 27 millones de dólares (Aroma y Sabor, abr.-may. 2003), cifras que representan cerca del $10 \%$ del volumen y el $15 \%$ del valor en dólares del total de café de todo tipo exportado por el Perú.

Es necesario aclarar que este nicho presenta cierto grado de complejidad, ya que incluye distintas categorías de café. Por ejemplo, los cafés sustentables se caracterizan por ser cultivados bajo estrictas normas internacionales que promueven la conservación de la salud, del medio ambiente y un comercio más justo; no implican necesariamente una mejor calidad del producto. Por otro lado, los cafés de alta calidad compiten sobre la base, valga la redundancia, de la calidad. En la década pasada el café sustentable se benefició con sobreprecios o primas altas, pero a medida que más países han ingresado a este mercado, los sobreprecios se han trasladado al café de alta calidad (Vieto, 2004).

Algunas organizaciones peruanas ya han percibido lo complejo del mercado. Luego de haber obtenido certificaciones por cafés sustentables, ahora orientan sus esfuerzos a mejorar la calidad del café y, con ello, están ganando el reconocimiento internacional y la preferencia de diversos países europeos, Estados Unidos y Japón (Maximixe, 2002). No obstante, los productores de cafés especiales son todavía muy pocos dentro del sector cafetalero peruano; la gran mayoría continúa atrapada en la crisis de precios sin poder romper el círculo de la pobreza.

Ante esta problemática, surge la pregunta de cómo lograr que una mayor cantidad de caficultores peruanos se beneficien de la oportunidad que representa el café de especialidad. En las condiciones actuales, es evidente que el sector necesita organizaciones con visión estratégica, capacidad de gestión y acceso a recursos financieros. Sólo así podrá lograr la tecnología agrícola, el conocimiento del mercado internacional y otras capacidades -negociar alianzas estratégicas- que le permitan obtener un producto en las condiciones exigidas por 


\title{
Café peruano obtiene Medalla de Oro en Concurso Mundial realizado en París
}

\author{
Nota de Prensa 302-04
}

El exigente jurado calificador del Trigésimo Primer Concurso Internacional de Cafés del Mundo quedó maravillado por la fineza del grano peruano al que otorgó la Medalla de Oro de esta competencia en la que participaron 33 variedades de café de los cuatro continentes, la cual tuvo como marco el World Ethnic \& Specialty Food Show, realizado en París el 15 y 16 de junio.

Conformado por destacados especialistas del mundo del vino, la gastronomía y el café, el jurado degustó a ciegas cafés seleccionados de una quincena de países productores tales como Colombia, El Salvador, República Dominicana, India, MéxiCo, países africanos, entre otros. Es así que el café peruano superó en calificación a granos de fama internacional.

El café ganador es de la variedad «arábica lavada», que proviene del valle de Villarica (Pasco) de la Cooperativa Coopchebi, del señor Dagoberto Marín Ludeña, miembro de la Asociación Peruana de Cafés Especiales (Apecafé), institución que participó con apoyo de la Embajada de Perú en Francia y de Prómpex como expositora en la Feria World Ethnic Food Show.

El balance perfecto de sus cualidades de buena acidez, excelente aroma y cuerpo medio fue lo que sedujo del café peruano al jurado del certamen. Cabe indicar que los productores aportan a este tipo de café criterios de calidad muy elevados, los cuales son garantizados por pautas de producción muy rigurosas.

«Este concurso permitió hacer descubrir a todos los visitantes europeos nuestros cafés finos y gourmets», señalaron regocijados por el galardón los representantes de Apecafé, quienes están empeñados en conquistar el nicho de mercado de los cafés finos. Y de hecho ya lo han conseguido, pues dos de sus variedades han sido incorporadas en la gama de productos gourmet de la famosa cadena francesa Hédiard.

Cabe indicar que el café representa el segundo mercado de materias primas en el mundo. No sólo es la palabra más utilizada en todas la lenguas y una bebida consumida en todos los países, sino que 80 naciones reúnen 25 millones de productores disgregados entre los Trópicos de Cáncer y Capricornio. Además, esta actividad significa el sustento para 125 millones de personas.

Hace una década, Vietnam se lanzó a la producción de café, lo que provocó el desplome de los precios y una crisis mundial en el mercado. Entonces algunos productores, para diferenciarse pero también para valorizar sus productos, decidieron proponer cafés finos que no sufrirían ninguna mezcla y serían objeto de una atención particular.

Actualmente, estos cafés de excepción, entre los que se encuentra el café peruano galardonado, representan sólo el $1 \%$ de la producción mundial. Los cafetales son cultivados en altitud, en medio del sol. Sus granos son recogidos a mano cuando ellos llegan a madurar, lavados y luego secados al sol, para ser finalmente rigurosamente seleccionados. 
este nicho de mercado. Todo esto requiere de la participación activa y organizada de los caficultores.

Este documento está dividido en tres partes. En la primera se explican los principales conceptos asociados al café de especialidad, así como los diversos determinantes de la calidad del producto. La segunda parte analiza las actuales tendencias del mercado internacional del café, con énfasis en el nicho de especialidad. La tercera parte se dedica al análisis del sector de la caficultura en el Perú; se identifican las ventajas comparativas que favorecen la obtención de un producto competitivo que satisfaga las exigencias del mercado, así como los problemas más comunes que deben enfrentarse para poder exportar.

La investigación ha comprendido amplia revisión de literatura, visitas a los campos de cultivo y entrevistas en profundidad con los principales actores de la cadena productiva del café, tanto privados como públicos.

\section{Consideraciones previas sobre el café de especialidad}

El café proviene de un arbusto originario de Etiopía, cuyas semillas tostadas y molidas constituyen una de las bebidas más consumidas en el mundo.

El café de especialidad, por su parte, es aquel café en el cual el consumidor reconoce características muy particulares por las que está dispuesto a pagar un mayor precio. Estas particularidades pueden estar relacionadas con las cualidades organolépticas de la infusión (café de alta calidad o de grado especial), con su ori- gen único y de calidad permanente (café gourmet) o con estándares estrictos de cultivo y/o comercialización (café sustentable). El mercado del café de especialidad también incluye, aunque en mucho menor cuantía, a aquellos cafés preparados con técnicas especiales que pueden enmascarar una menor calidad del café, como es el caso de los cafés aromatizados o del café exprés o expresso.

\subsection{El café de alta calidad}

La calidad del café se evalúa considerando tanto las condiciones físicas del grano como las cualidades de la infusión o «taza» de café, pero la calidad del grano verde determina buena parte de la calidad de la infusión, ya que los defectos ${ }^{1}$ del grano originarán sabores desagradables en la bebida.

Los diversos sistemas de clasificación de la calidad del grano verde ${ }^{2}$ consideran

1. Los defectos son imperfecciones encontradas en el aspecto exterior del grano: granos manchados, partidos, afectados por insectos, partículas extrañas, etc. Estos defectos pueden ser intrínsecos (granos alterados por los procesamientos agrícolas e industriales o por modificaciones genéticas o fisiológicas) o extrínsecos (presencia de elementos extraños en el café beneficiado). De acuerdo con la clasificación usada para valorar el café verde, un grano negro puede considerarse un defecto, mientras una piedra grande puede equivaler a 5 defectos, y así por el estilo.

2. El Centro de Comercio Internacional usa criterios cualitativos y clasifica los cafés en: ejemplar, superior, normal o corriente y descarte. El Brazil / New York Method, de la Green Coffee Association, clasifica el café por el porcentaje de defectos en muestras de 300 gramos: NY2 significa que hay 4 defectos por 300 gramos de café; NY3, que hay 12, y así sucesivamente hasta llegar a NY8. La clasificación brasileña por tipos admite 7 valores de 2 a 8 , también en función de los defectos encontrados en muestras de 300 gramos. 


\section{Cuadro 1}

Clasificación del grano verde por SCAA

\begin{tabular}{|l|c|c|c|}
\hline \multicolumn{1}{|c|}{ Grado } & $\begin{array}{c}\text { Número máximo } \\
\text { de defectos } \\
\text { en } \mathbf{3 0 0} \mathbf{g} \text { de café }\end{array}$ & Humedad & $\begin{array}{c}\text { Variación del } \\
\text { tamaño de } \\
\text { grano indicado }\end{array}$ \\
\hline Especialidad (1) & 5 & $9-13 \%$ & $\pm 5 \%$ \\
Premium (2) & 8 & $9-13 \%$ & $\begin{array}{c} \pm 5 \% \\
\text { Intercambio (3) }\end{array}$ \\
Estándar bajo (4) & $9-23$ & $9-13 \%$ & $\begin{array}{c}50 \% \text { del peso encima } \\
\text { de malla número 15, } \\
\text { con no más de } 5 \% \\
\text { de malla número 14 } \\
\text { Fuera de grado (5) }\end{array}$ \\
\hline
\end{tabular}

Fuente: [http://www.coffeeresearch.org/coffee/scaaclass.htm].

desde criterios cualitativos, como el color, hasta criterios cuantitativos, como el tamaño, número de defectos y grado de humedad contenido. El sistema de mayor vigencia es el de la Specialty Coffee American Association (SCAA), no sólo porque es usado oficialmente en el café que se comercializa en Estados Unidos -el mayor mercado de café de especialidad del mundo-, sino, sobre todo, porque relaciona mejor la calidad del grano verde con la calidad hallada en la infusión.

Por su parte, la calidad de la infusión, que es el principal factor para captar al consumidor final de café especial, se evalúa mediante una «prueba de taza»-llamada simplemente «taceo»-, que identifica las cualidades de fragancia-aroma, sabor, sabor residual, acidez, cuerpo, balance, uniformidad, dulzor, defectos e impresión general de la bebida. Sobre la base de 100 puntos, un café es considerado de grado especialidad si sobrepasa los 80 puntos.

La base para un café de alta calidad se encuentra en la combinación de distintos factores: la variedad de la planta, la altura de la zona de cultivo, las condiciones edáficas y el manejo de la cosecha y la poscosecha (Castañeda, 2000).

La variedad botánica influye en la calidad de taza, pues determina el cuerpo, aroma y acidez del café. Dos son las principales variedades botánicas comercializadas en todo el mundo: la variedad arábica y la variedad robusta. El café de variedad arábica (Coffea arabica) -que a su vez se subdivide en dos variedades: -typica y bourbon- tiene un aroma complejo y una acidez pronunciada, por lo cual es valorado como de mejor calidad y es el más apreciado por el mercado de cafés especiales. El café de variedad robusta (Coffea canephora) tiene mucho cuerpo, es muy amargo y su aroma es poco complejo. Debido a que su calidad es menor, se utiliza principalmente para la producción de café soluble, y su presencia en el mercado de especialidad está limitada al tipo de café preparado como expresso o a los cafés sustentables.

La altitud donde se desarrollan los cultivos de café influye sobre todo en el grado de acidez. A mayor altura, mayor acidez y mejor calidad. Además, la altura 
determina las variedades de café, pues los de la variedad arábica se adaptan a alturas mayores a los 1200 m.s.n.m. Por ello, los cafés vendidos con el lema «estrictamente de altura» se refieren a los cultivados entre los 1200 y 2000 m.s.n.m, y son los más apreciados.

La región donde se produce puede influir sobre el aroma del café. Los cafés más apreciados son los de aromas y sabores ligeramente afrutados o florales.

La calidad del café puede ser vulnerada por un inadecuado manejo de la cosecha o la poscosecha. El café convencional pasa por una serie de procesos desde su cosecha hasta su consumo, procesos que son los mismos en el café de especialidad. La diferencia reside en la forma cómo se llevan a cabo. La figura 1 muestra esquemáticamente el proceso productivo del café de especialidad y el estricto control de calidad que debe aplicarse para obtener un producto de excelencia.

\subsection{El café gourmet}

Una vez obtenido un café de alta calidad, en la medida en que esta calidad sea constante en el tiempo se habrá logrado un café gourmet, el cual es el más valorado y el que alcanza los más altos precios del mercado.

El café gourmet se produce generalmente en volúmenes reducidos, porque está asociado a un origen único (como el Jamaican Blue Mountain Coffee), una anécdota o leyenda particular o un lugar exótico (como el café de las islas Galápagos, Ecuador).

\subsection{El café sustentable}

Aunque no necesariamente acompañados por la mejor calidad, los cafés sustentables son valorados en el mercado de especialidad por lo que representan para el consumidor final: el cumplimiento de estándares que garantizan prácticas agrícolas ecológicas, sanitariamente inocuas y comercialmente equitativas. A fin de aumentar su confiabilidad y credibilidad, los cafés sustentables requieren para comercializarse de certificaciones o sellos otorgados por agencias reconocidas internacionalmente, que inspeccionan y supervisan el cumplimiento de los estándares mencionados.

Así, el café orgánico, un tipo de café sustentable, se cultiva sin pesticidas ni agroquímicos, tanto para conservar la salud del agricultor y del consumidor, como para fomentar la conservación de la diversidad y estabilidad del medio ambiente. Las certificaciones reconocidas son las otorgadas por OCIA, en Estados Unidos y por Naturland y Eco-OK en Europa, mientras en el Japón los productos orgánicos son comercializados con el sello JAS. El cultivo del café orgánico peruano se desarrolla principalmente por iniciativa de diversas cooperativas y empresas privadas, con recursos propios o con apoyo internacional.

Otro café sustentable es el cultivado bajo sombra, llamado también «café amigable con las aves». En este caso el grano se cultiva en un sistema agroforestal equilibrado, evitando la deforestación y conservando la biodiversidad. La iniciativa fue creada por el Smithsonian Migratory Bird Center (SMBC), que otorga el sello Bird Friendly ${ }^{\circledR}$. Otra certificación que ha empezado a ganar reconocimiento de los consumidores es la otorgada por la Rainforest Alliance. 


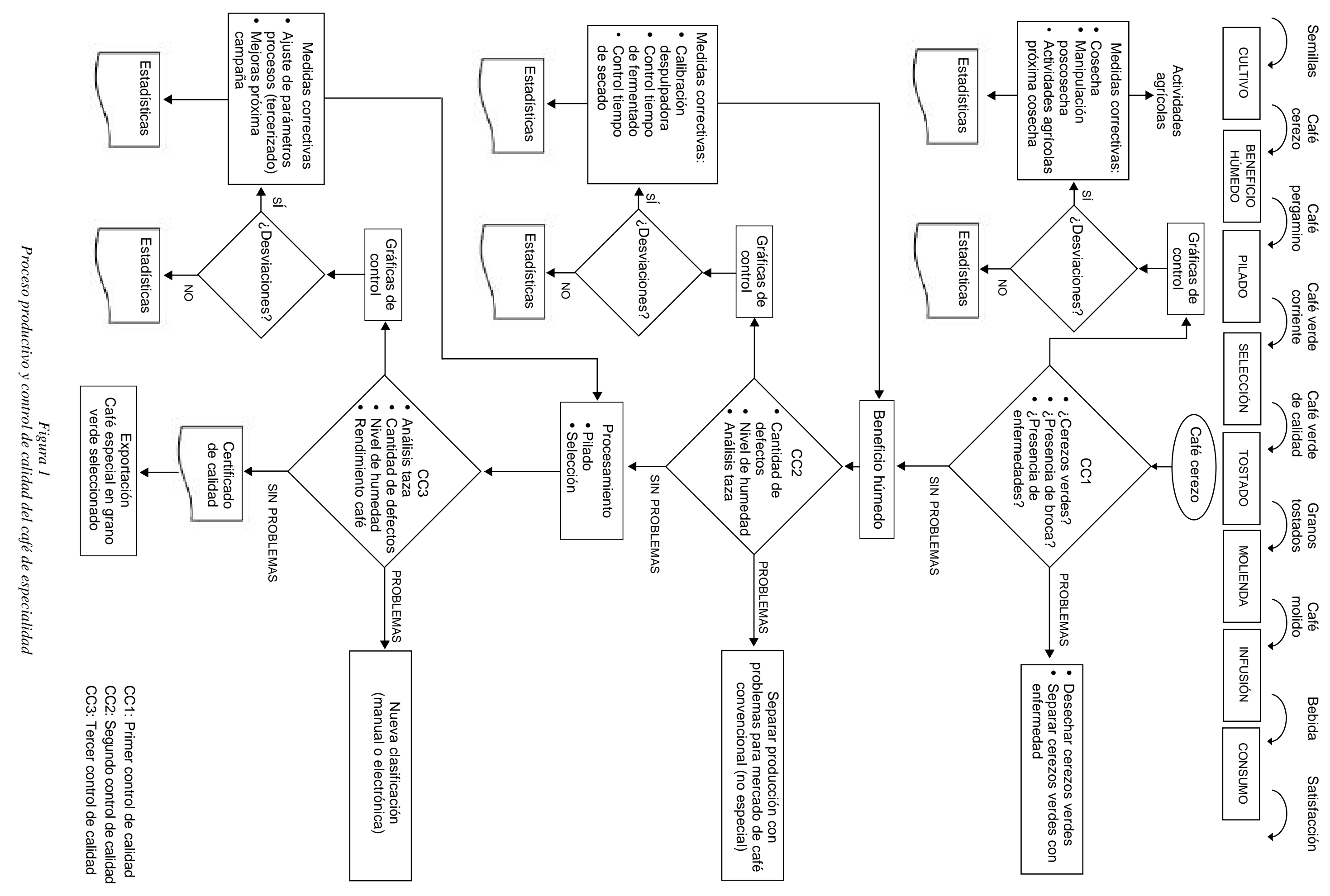



Por último, también es sustentable el café de Comercio Justo, que nació en 1989 como un sistema de protección al agricultor frente a los bajos precios internacionales. El café que es comercializado en este sistema obliga al importador a pagar un precio mínimo que garantiza al agricultor la recuperación de su inversión en la producción y un margen para su subsistencia, lo cual es valorado por el consumidor. El sistema es representado por la Fairtrade Labelling Organization (FLO), cuyos miembros, las agencias certificadoras o iniciativas nacionales, son las que inspeccionan y supervisan el cumplimiento de las condiciones del Comercio Justo, desde el caficultor hasta la venta al público consumidor.

\section{El mercado internacional del café de especialidad}

La información relativa al café de especialidad está comprendida dentro del mercado convencional de café, ya que hasta la fecha no hay una partida arancelaria específica que diferencie el producto. Ante la falta de datos oficiales, las estadísticas privadas se recogen por medios alternativos, como investigaciones de mercado e informes de las entidades certificadoras o de las agrupaciones de productores.

El café se cultiva en zonas de clima tropical, motivo por el cual los países productores están ubicados cerca de la línea ecuatorial. Por lo general son países en vías de desarrollo que, aunque sea paradójico, presentan los menores volúmenes de consumo de esta bebida, con excepción de Brasil y Colombia. El café peruano está catalogado dentro del tipo Otros suaves. Este y el tipo Suaves son los cafés más apreciados por los consumidores y de ellos proviene la mayoría de los cafés de especialidad (Centro de Comercio Internacional UNCTAD/GATT, 2002).

Del volumen anualmente producido de todo tipo de café en el mundo, más del $50 \%$ corresponde a tres países: Brasil, Colombia y Vietnam. El Perú contribuye apenas con el 2,34\% del total (Castañeda, 2004).

Según, la Organización Internacional del Café (OIC), entre el $10 \%$ y el $15 \%$ del café producido mundialmente se comercializa en el mercado de especialidad, en tanto que el Centro de Inteligencia de Mercados Sostenibles (CIMS) establece que este porcentaje es de $6 \%$, del cual $5 \%$ sería café gourmet o de alta calidad y sólo $1 \%$ correspondería a café con certificaciones sustentables (Villalobos, 2004b).

A pesar de sus cifras más conservadoras, el CIMS estima que el mercado de café de especialidad crecerá a mayor ritmo que el café convencional. Esto porque el café convencional sigue una tendencia de precios bajos y venta por volumen que ha ocasionado el deterioro progresivo de su calidad. Luego, hay una demanda insatisfecha que exige mayor calidad y está dispuesta a pagar por ella precios más altos.

El consumo del café está concentrado en países no productores, ubicados en el hemisferio norte. El 75\% del consumo mundial corresponde a sólo seis países: Estados Unidos, Alemania, Japón, Italia, Francia y España, cuya población tiene alto poder adquisitivo y orienta su consumo hacia productos de buena calidad $\mathrm{y}$, en el caso del café, hacia el café de especialidad (Castañeda, 2004) 
Cuadro 2

Países productores por tipo de café

\begin{tabular}{|c|lc|}
\hline \multicolumn{2}{|c|}{ Arábicas: Coffea arabica } & \% producción \\
\hline Suaves & Colombia, Kenia, Tanzania, Brasil & $20 \%$ \\
\hline Otros suaves & $\begin{array}{l}\text { Burundi, Costa Rica, Cuba, República Dominicana, } \\
\text { Ecuador, El Salvador, Guatemala, Haití, Honduras, } \\
\text { India, Jamaica, Malawi, México, Nicaragua, Panamá, } \\
\text { Papúa Nueva Guinea, Perú, Ruanda, Venezuela, } \\
\text { Zambia, Zimbabue. }\end{array}$ & $12 \%$ \\
\hline Otros arábicas & Bolivia, Brasil, Etiopía, Paraguay. & $36 \%$ \\
\hline Robustas & Robustas: Coffea canephora & \\
& $\begin{array}{l}\text { Angola, Ghana, Indonesia, Liberia, Nigeria, Filipinas, } \\
\text { Sierra Leona, Sri Lanka, Tailandia, Trinidad y Tobago, } \\
\text { Uganda, Vietnam, República Democrática del Congo } \\
\text { (Zaire) y los países de la OAMCAF*: Benín, Camerún, } \\
\text { República Centroafricana, Congo, Costa de Marfil, } \\
\text { Guinea Ecuatorial, Gabón, Madagascar y Togo. }\end{array}$ & $32 \%$ \\
\hline
\end{tabular}

Fuente: Ministerio de Agricultura (Minag).

* The African and Madagascan Coffee Organization.

\section{Cuadro 3}

Principales países productores de café

(Participación en la producción mundial de todo tipo de café)

\begin{tabular}{|lcc|}
\hline País productor & $\%$ & Tipo de café \\
\hline Brasil & $28,00 \%$ & Arábica, robusta \\
Colombia & $12,00 \%$ & Arábica \\
Vietnam & $11,00 \%$ & Robusta \\
Perú & $2,34 \%$ & Arábica \\
Otros (47 países aproximadamente) & $46,66 \%$ & - \\
Total (todo tipo de café) & $100,00 \%$ & - \\
\hline
\end{tabular}

Fuente: Castañeda, 2004: 10.

Cuadro 4

Tasa de crecimiento anual

del mercado

\begin{tabular}{|lr|}
\hline Tipo de café & Tasa de crecimiento \\
\hline Café convencional & $1-2 \%$ \\
o genérico & $5-10 \%$ \\
Café gourmet & + de $10 \%$ \\
Café comercio justo & $5-20 \%$ \\
Café orgánico & \\
\hline
\end{tabular}

Centro de Inteligencia de Mercados Sostenibles, 2004. 


\section{Cuadro 5}

Principales países consumidores de café (Participación en el consumo mundial de todo tipo de café)

\begin{tabular}{|lc|}
\hline País consumidor & Participación \\
\hline Estados Unidos & $27 \%$ \\
Alemania & $19 \%$ \\
Japón & $8 \%$ \\
Italia & $8 \%$ \\
Francia & $8 \%$ \\
España & $5 \%$ \\
Otros & $25 \%$ \\
Total & $100 \%$ \\
\hline
\end{tabular}

Fuente: Castañeda, 2004: 10.

Los contratos de compra y venta del café arábica no especial, también llamado café convencional o genérico, se negocian en la Bolsa de Productos de Nueva York, conocida como NYBOT (New York Board of Trade). En esta bolsa se comercializan los contratos futuros del café y los precios se definen (precio «C» de Nueva York o precio NYBOT) según el libre juego de la demanda y oferta.

Con pocas excepciones -como la ocurrida en 1997 cuando las heladas en Brasil ocasionaron la pérdida de la producción y un déficit considerable en la oferta mundial-, la oferta supera la demanda y, en consecuencia, los precios del café convencional tienden a la baja. Según su historial de calidad, algunos países obtienen premios o castigos aplicados sobre el precio de bolsa. Gracias a la mejora sostenida de la calidad del café peruano y a las gestiones realizadas por la Cámara Peruana del Café, en el año 2004 se eliminó el castigo que el café peruano sufría en las compras a futuro (Cámara Peruana del Café, 2003).

Por el contrario, el precio del café de especialidad es resultado de la negocia- ción directa entre comprador y vendedor realizada fuera de la bolsa de productos, es decir, en el mercado físico del café. El precio NYBOT es usado sólo como base o referencia; a partir de este se negocian sobreprecios o primas en función de la calidad del café y/o de las certificaciones sostenibles que reúna (Vieto, 2004c). Sin embargo, como se muestra en la figura 2, el mercado valora más la calidad que las certificaciones. Por ello, si bien inicialmente la certificación fue una alternativa para afrontar la crisis del café, hoy ya no es suficiente.

Adicionalmente, como muestra la $f i$ gura 3, desde el punto de vista de los intermediarios, el factor más importante para la venta de café sustentable es la calidad del producto, mientras las exigencias de certificación tienen pesos claramente menores (Giovannucci, 2001). Los indicios señalan que la propia industria ha desempeñado un papel crucial en el desarrollo del mercado de los cafés sustentables simplemente con ofrecer estos productos certificados. Hoy la demanda del café de especialidad está creciendo más por la calidad del producto que por la certificación, situación que incrementa considerablemente las oportunidades para la expansión del mercado.

Por otro lado, la figura 4 muestra que para las decisiones de compra a los exportadores, los precios bajos no son determinantes; existe una clara preferencia del mercado por la calidad estable y predecible, así como por la consistencia del suministro.

Los mayores mercados para el café de especialidad son Estados Unidos, la Unión Europea y Japón, de los cuales el primero es el más importante (como se observa en 


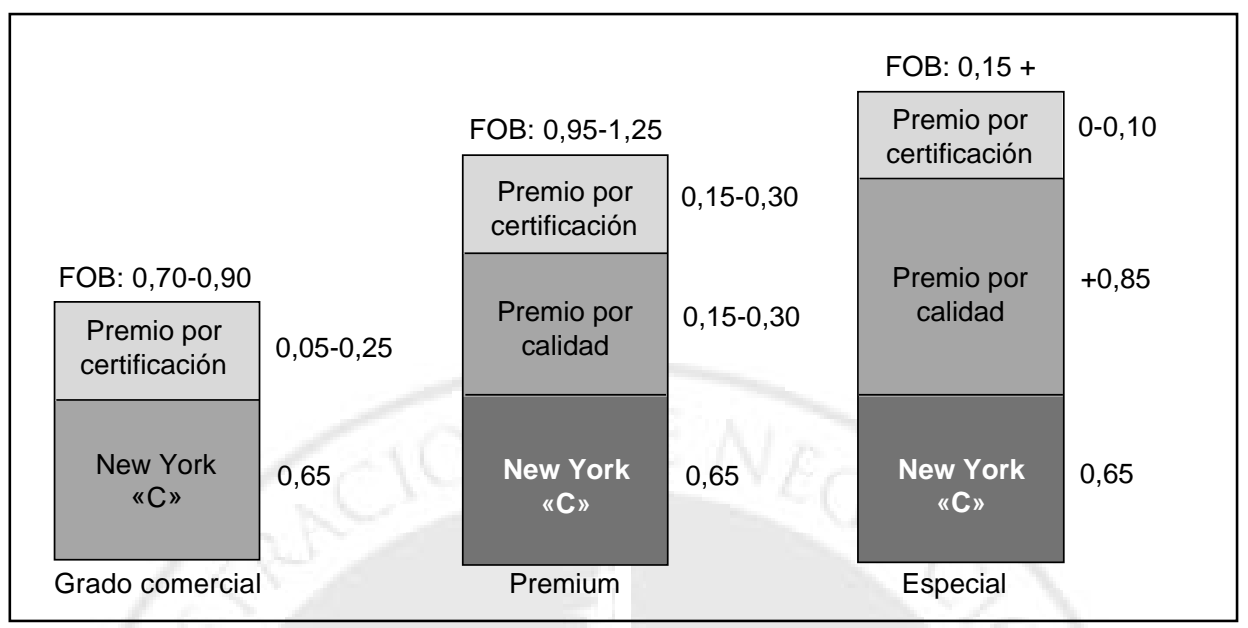

Fuente: Centro de Inteligencia de Mercados Sostenibles, 2004.

Figura 2

Estructura del precio FOB en el mercado de especialidad (en US $\$ / l b$ café verde)



Fuente: Giovannucci, 2001.

Figura 3

Factores considerados muy importantes por los intermediarios en el caso del café sustentable

el cuadro 6) debido a la demanda insatisfecha, las tasas de crecimiento y los volúmenes importados. Por otro lado, China, con sus más de 1300 millones de habitantes y más de 40 millones de millonarios, se perfila como un mercado potencial, en la medida en que su población, tradicionalmente consumidora de té, está variando sus hábitos de consumo por su acercamiento comercial y cultural a los países de Occidente.

El café de especialidad, a diferencia del café convencional, suele venderse 
sobre la base de muestras o descripciones individualmente convenidas entre el exportador, el importador y el tostador. Se debe contar con muestras de cada cosecha para el envío a minoristas. Inicialmente la compra estará supeditada a la apro- bación de la muestra hasta que se garantice el suministro y la calidad en forma continua al tostador. Posteriormente se podrá utilizar el sistema de muestra de lote en existencia, de modo que en vez de enviar muestras en cada contrato se ofrece

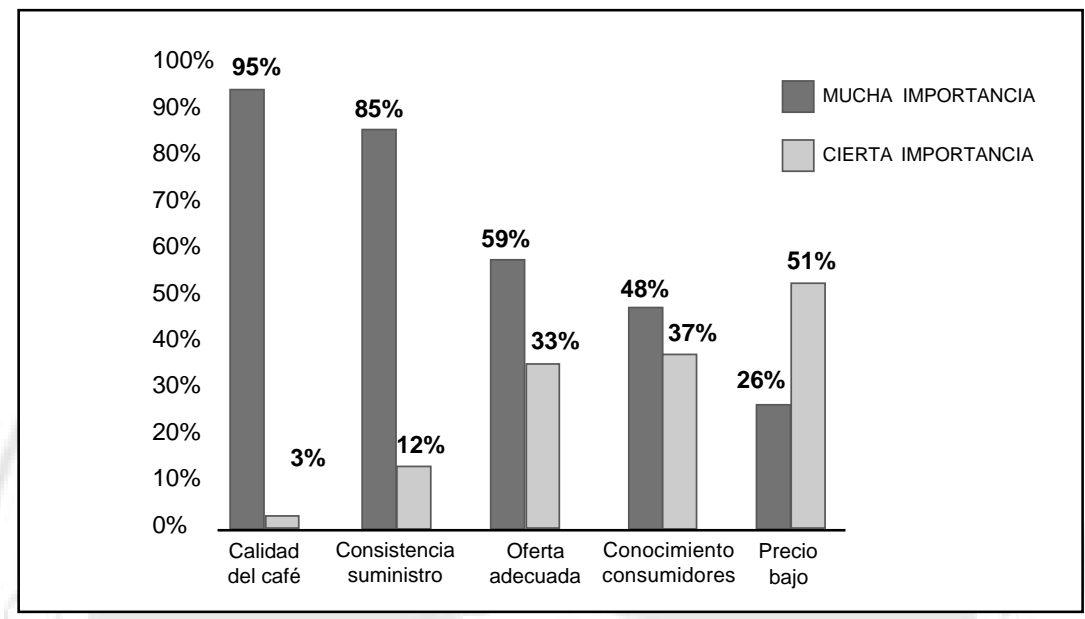

Fuente: Giovannucci, 2001.

Figura 4

Importancia de los atributos para el comercio de café sustentable

\section{Cuadro 6}

Características de los principales mercados de café de especialidad

\begin{tabular}{|l|c|c|c|}
\hline \multicolumn{1}{|c|}{ Características } & Estados Unidos & Europa & Japón \\
\hline $\begin{array}{l}\text { \% café especial sobre } \\
\text { importaciones del } \\
\text { país 2002 (aproximado) }\end{array}$ & $\begin{array}{c}20 \% \\
(3,9 \text { millones de sacos) }\end{array}$ & $\begin{array}{c}3 \% \\
(1,3 \text { millones de sacos) })\end{array}$ & $\begin{array}{c}0,4 \% \\
(27 \text { mil sacos })\end{array}$ \\
\hline Crecimiento alcanzado & $\begin{array}{c}30 \% \\
\text { (últimos 5 años) }\end{array}$ & $5-15 \%$ & $\begin{array}{c}196 \% \\
(2001-2002)\end{array}$ \\
\hline Crecimiento esperado & $10 \%$ a 20\% & Mucha & Muy poca \\
\hline Demanda insatisfecha & $\begin{array}{l}\text { Mlta motivación de } \\
\text { consumidores por beber } \\
\text { café de mejor calidad. }\end{array}$ & $\begin{array}{l}\text { Diversidad de } \\
\text { comportamientos por } \\
\text { países: diferentes } \\
\text { preferencias respecto } \\
\text { al sabor y aceptación } \\
\text { de certificaciones. } \\
\text { Pagan precios más } \\
\text { bajos que en EE. UU. }\end{array}$ & $\begin{array}{l}\text { Mercado complicado } \\
\text { y cambiante. Pagan } \\
\text { buen precio por } \\
\text { calidad. Certificación } \\
\text { más exigente. }\end{array}$ \\
\hline Otras características
\end{tabular}

Villalobos, 2004a, 2004c y 2004d. 
«calidad equivalente al lote $\mathrm{x}$ ». Cuando las transacciones del sistema de muestra del lote en existencia han sido satisfactorias, se puede convenir con el comprador clasificar la calidad en un tipo determinado. De esta manera, las transacciones pueden continuar sin necesidad de muestras y con la confianza de ambas partes en que la calidad será respetada (Centro de Comercio Internacional UNCTAD/GATT, 2002).

Hay un canal de reciente aparición, el de la subasta electrónica ${ }^{3}$, utilizado por los caficultores del tipo gourmet en otros países con el fin de obtener mejores precios en el mercado internacional. En Costa Rica se ha logrado hasta triplicar el precio de venta del café con este sistema. Para participar en esta subasta, es necesario que la calidad del producto sea calificada previamente por expertos nacionales e internacionales.

\section{Breve panorama de la caficultura en el Perú}

El café es de gran importancia para la economía nacional. Por un lado, es el principal producto agrícola de exportación y genera casi el 30\% de las divisas del sector agropecuario (Ministerio de Agricultura, 2004).

Por otro lado, de acuerdo con el III Censo Nacional Agropecuario, de 1994, el cultivo del café es fuente de ingresos para 105545 productores, de los cuales 25 mil se dedican al cultivo de café especial orgánico certificado. No obstante, el café beneficia en total a aproximadamente 600 mil peruanos repartidos a lo largo de toda

3. Uno de ellas es The cup of excellence [http:// www.cupofexcellence.org]. la cadena de valor: productores, comerciantes, acopiadores, transportistas, distribuidores, tostadores, comerciantes grandes y pequeños, administradores, entidades financieras, exportadores, profesionales y técnicos, entre otros agentes económicos. Cada hectárea de café da empleo permanente, directa o indirectamente, a cuatro peruanos.

Por razones como las expuestas, es evidente la necesidad de analizar la competitividad del sector cafetalero peruano como cuestión previa para canalizar las iniciativas dirigidas a lograr una oferta exportable de reconocimiento mundial. En la cadena productiva del café peruano se diferencian claramente tres eslabones: a) producción, b) transformación (beneficio y procesamiento) y c) comercialización. A continuación se detallan las principales ventajas comparativas y los «cuellos de botella» identificados en cada uno de estos eslabones.

\subsection{Eslabón productivo}

\section{Áreas de cultivo y variedades}

Las áreas de cultivo del café se encuentran distribuidas en toda la vertiente oriental de los Andes, que es la zona más propicia para este producto por las características de los suelos, el clima, la altura y el régimen de lluvias; sin embargo, esta zona está considerada también como la más critica, ya que contiene el mayor número de ecosistemas del mundo amenazados por las actividades humanas. Por ello, un cultivo de café que respete el ecosistema será mejor valorado en los mercados de consumo preocupados por la ecología.

En el Perú, el café se cultiva en zonas accidentadas de pendientes inclinadas, 
entre los 800 y 1850 m.s.n.m. y con precipitaciones que varían entre 800 y 2500 $\mathrm{mm}^{3}$ por año. Gracias a esta combinación de climas, suelos, precipitación y luz solar, el Perú es un escenario ventajoso para el cultivo del café, sobre todo para el café de especialidad, habida cuenta de que el $75 \%$ de los cafetales se desarrollan por encima de los 1000 m.s.n.m. (Cámara Peruana del Café, 2002).

Casi el 100\% de los cafés del Perú son Coffea arabica, aunque de diferentes perfiles de sabor, aroma y acidez. Se estima que el $70 \%$ de cafetales corresponden a la variedad typica, de la cual se obtiene una excelente calidad de taza. Además, el $90 \%$ del café peruano crece bajo sombra de árboles, principalmente de leguminosas, que le aportan nutrientes naturales a la vez que protegen la biodiversidad de la flora y la fauna. Esta característica facilita las certificaciones de los cafés sustentables bajo sombra y orgánicos (Cámara Peruana del Café, 2002).

\section{Producción y precios}

Se estima que el cultivo del café en el Perú ocupa una extensión total de 285 mil hectáreas sembradas, de las cuales $42 \mathrm{mil}$ hectáreas son orgánicas certificadas. El café se produce en 210 distritos rurales ubicados en 47 provincias de 10 departamentos, de los cuales, Cusco, Junín, Cajamarca, San Martín y Amazonas representan el $87,4 \%$ de la producción.

Según la Junta Nacional del Café (2004), se calcula que en el 2004 la producción alcanzará una cifra récord de aproximadamente 4,43 millones de quintales de café. Sin embargo, como se puede observar en la figura 5, aunque el volumen exportado aumenta desde 1997, los montos de exportación disminuyen considerablemente. Esto refleja el constante deterioro de la relación precio-volumen.

Los precios promedio en chacra del café han seguido por norma general la tendencia de los precios internacionales ( $f i$ gura 6), pues la mayoría es café convencional. En los últimos años ha habido una redistribución del ingreso hacia los productores, probablemente por la mejor gestión de las organizaciones que están comercializando cada vez mayor volumen de café de especialidad, lo que ha contribuido a retener para el productor una parte mayor del precio internacional.

Técnicas de producción, productividad y calidad

Este estancamiento en la producción es causado, en primer lugar, por la escasa productividad promedio de los campos -estimada en el 2001 en alrededor de 15 quintales por hectárea al año-, relacionada principalmente con el poco desarrollo tecnológico de los cultivos. El 80\% de las unidades agrícolas que se dedican al cultivo del café mantienen todavía un sistema tradicional de técnicas rudimentarias heredadas de sus ancestros; un rasgo común en casi toda la agricultura peruana (Ministerio de Agricultura, 2004). Además de la baja productividad, la mayoría de los caficultores ni siquiera conoce la calidad de su producto, que casi siempre es inferior. Esta realidad contrasta con lo obtenido por algunos productores que, tras haber mejorado su tecnología, han multiplicado con creces su productividad y la calidad de su café.

La mayoría de las labores agrícolas cafetaleras son llevadas a cabo por mano 


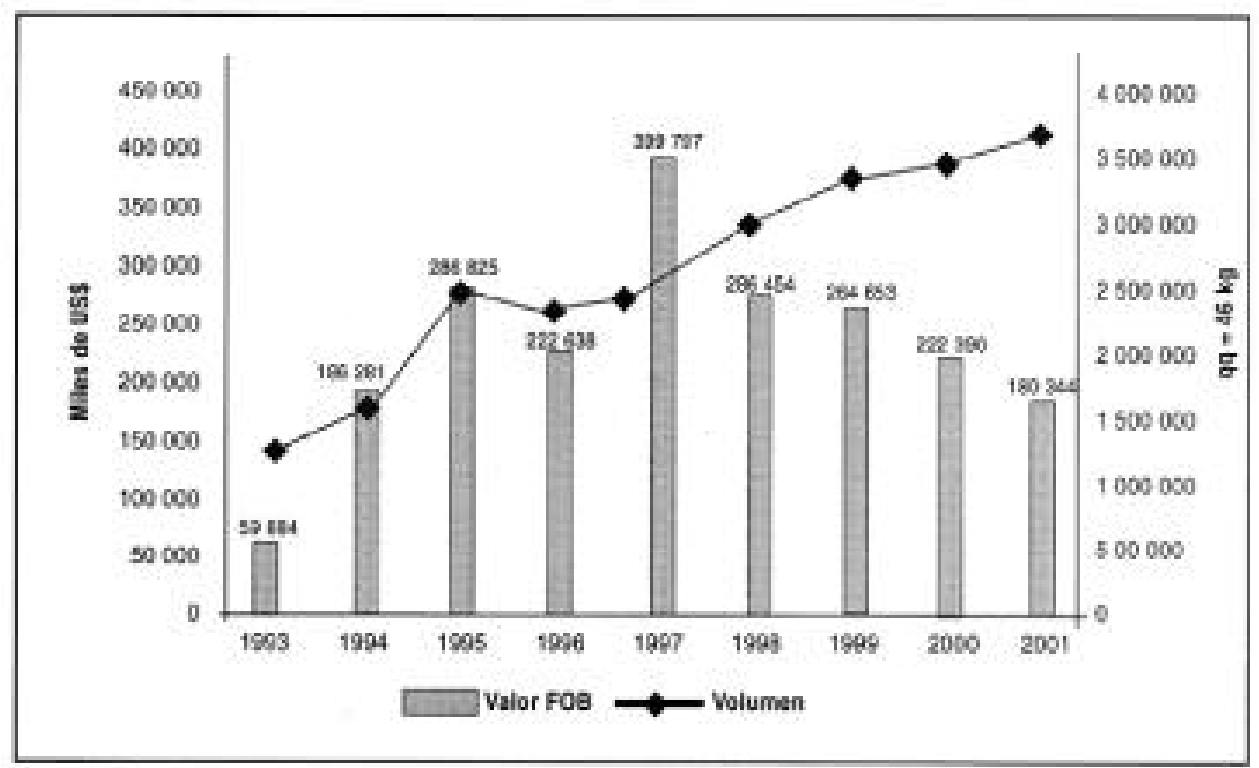

Fuante: Superintendencia Nacional de Administración Tributaria.

Figura 5

Volumen y valor de expontación de café verde

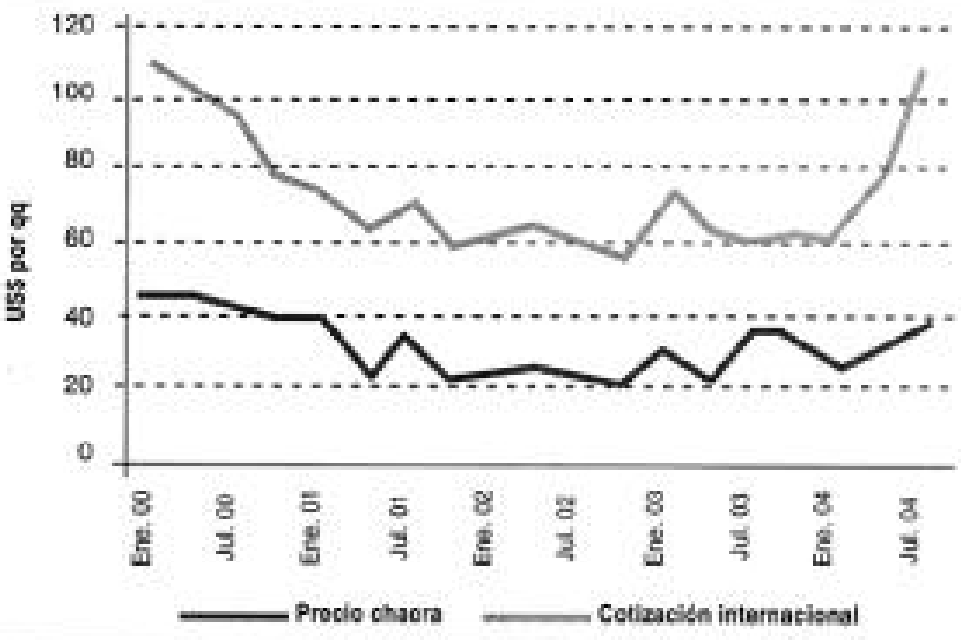

Fuente: Ministarlo de Agricultuas.

Figura 6

Precios en chacra y cotización internacional del café

(onc. 2000-jul 2004) 


\section{Cuadro 7 \\ Uso de tecnología cafetalera}

\begin{tabular}{|lcccc|}
\hline Tipo de tecnología & (\%) & Hectáreas & $\begin{array}{c}\text { Rendimiento } \\
\text { (qq/ha) }\end{array}$ & $\begin{array}{c}\text { Producción total } \\
\text { (en qq) }\end{array}$ \\
\hline Sin tecnología & 80 & 186400 & 11 & 2050400 \\
\hline Tecnología media & 18 & 41940 & 28 & 1174320 \\
\hline Tecnología de punta & 2 & 4660 & 60 & 279600 \\
\hline
\end{tabular}

Fuente: Ministerio de Agricultura.

de obra familiar no remunerada; el empleo remunerado se concentra en los meses de cosecha, de marzo a agosto. Durante el resto del año el agricultor prefiere dedicarse al cultivo de productos de panllevar, mientras que descuida las labores culturales que el café necesita para mantener una productividad aceptable. Más aún, para contar con tierras para el cultivo de panllevar, el agricultor deforesta y aplica técnicas tradicionales de la sierra, las que al ser utilizadas en zonas de mayor pendiente ocasionan la erosión de la tierra y rompen el equilibrio del ecosistema. Así, en pocos años dicha tierra se vuelve infértil. Dado que el ciclo se repite año tras año, la deforestación acumulada se convierte en un problema que afecta tanto su economía individual -porque cada vez disminuye más su productividad y reduce su tierra- como el medio ambiente de todo el mundo.

Otro aspecto que merece atención es el incremento de las plagas que atacan el cultivo. La Junta Nacional del Café insiste en demandar acciones concretas para combatirlas, especialmente a la broca, cuyo daño llega hasta el $25 \%$ de la cosecha en algunas zonas cafetaleras. Un estimado general hecho por el Servicio Nacional de Sanidad Agropecuaria (Senasa) y técnicos del Ministerio de Agricultura refiere pérdidas por más de 15 millones de dólares en la campaña del 2004, las cuales podrían aumentar en el 2005 debido a la inactividad sanitaria del Ministerio de Agricultura (Aroma y Sabor, jun. 2004).

\section{Organización de las unidades productivas}

El bajo nivel de instrucción de los productores y la escasa armonía lograda por los pocos productores agremiados también impide establecer y desarrollar esfuerzos mancomunados orientados a objetivos comunes de desarrollo del sector. La frágil organización de los productores es la razón fundamental de la debilidad general del eslabón productivo del café. La mayoría son minifundistas (alrededor del $63 \%$ de ellos tienen menos de 10 ha), están altamente dispersos y carecen de títulos de propiedad; todo esto dificulta obtener un volumen de producción de calidad respetable para exportación, así como el acceso al financiamiento requerido para implementar mejoras tecnológicas. Además, el agricultor actúa con una visión de corto plazo cuando consume la totalidad de los ingresos que percibe por la venta de su producto, sin pensar en las futuras cosechas y el cuidado de las plantaciones.

Sólo el $25 \%$ de los productores están organizados en alguna cooperativa, asociación o comité. El resto son unidades 
productivas desarticuladas y atomizadas, lo que no permite desarrollar una producción a escala ni tener capacidad de negociación para la exportación. Debe aclararse en este punto que el minifundio en sí no es un obstáculo para el desarrollo de café de especialidad, pero sí lo es la desarticulación. El Comercio Justo, por ejemplo, presta mucha atención a que los beneficiarios del sistema sean pequeños productores, pero a la vez pone énfasis en la organización y la importancia del planeamiento estratégico.

Ejemplo de lo mencionado es que, a pesar de las limitaciones, la iniciativa privada ha mostrado un mejor desempeño en los últimos años y, aunque no es la generalidad, algunas organizaciones se han fortalecido adaptando su producción a las nuevas tendencias del mercado. En un inicio se han preocupado por obtener la certificación para ofertar café sustentable y, paulatinamente, están poniendo más cuidado en la calidad y también en la promoción del café.
Por ello, en materia de cafés especiales son las cooperativas o empresas cafetaleras privadas las que han logrado obtener café de alta calidad y/o con certificaciones que les han permitido acceder al mercado internacional. Tales son los casos de la Central de Cooperativa Agrarias Cafetaleras (Cocla), Cooperativa Bagua Grande, Villa Rica Highland, La Florida y Cecovasa, entre otras, cuyas exportaciones se están incrementando tanto en volumen como en destinos internacionales (Aroma y Sabor, jul. 2004). En estas experiencias exitosas ha jugado un papel decisivo la promoción del café peruano de alta calidad, a través del esfuerzo conjunto entre productores y gobierno, así como también la adecuada administración de los préstamos de ayuda internacional a la que han tenido acceso algunas de estas empresas, sobre todo al inicio de sus operaciones.

En el caso de los agricultores no asociados, la limitada organización y la producción individual sin asistencia técnica son las dos razones principales de la pér-

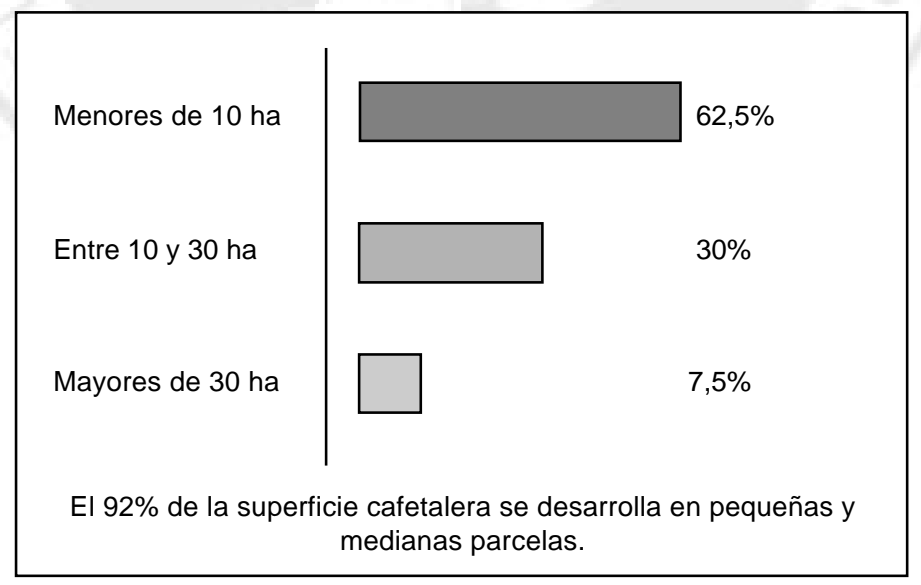

Fuente: Ministerio de Agricultura 
dida de rentabilidad y de la descapitalización. La mayoría de ellos no tienen acceso a créditos ni a financiamiento adecuado para el manejo de su unidad productiva. La falta de poder adquisitivo, en consecuencia, limita el acceso a servicios de certificación, asesoría técnica, tecnología y adquisición de insumos para mejorar rendimientos, elevar la productividad y obtener mejores precios.

Por otro lado, en la década del 80 la incursión de grupos subversivos deterioró la poca infraestructura productiva establecida y causó el abandono de gran número de cafetales o la conversión de éstos en cultivos de coca, destinada, sobre todo, al narcotráfico. Si bien esto mejoró los ingresos de algunos agricultores, también creó un deterioro moral del sistema social y familiar del que la zona se está lentamente recuperando gracias a los esfuerzos de diversas instituciones. Actualmente, el café es uno de los productos privilegiados en los proyectos de Desarrollo Alternativo - una de las acciones del país en su lucha contra el narcotráfico-. Sin embargo, el café convencional no ha podido representar una verdadera alternativa debido a las fluctuaciones de sus precios internacionales, por lo que el café de especialidad puede tomar su lugar como cultivo rentable.

Por todo lo expuesto hasta aquí, es obvio que los productores tendrán que organizarse para asumir los retos que demanda insertarse en el mercado internacional del café. Sin embargo, nuestra realidad exige que antes de elegir un modelo asociativo se profundice en las características propias de los agentes económicos involucrados. El sector agrícola peruano muestra una amplia variedad de modelos asociativos que deben ser analizados a fin de encontrar cuáles pueden adaptarse mejor a las circunstancias específicas de los productores cafetaleros: comités, asociaciones, cooperativas, empresas comunales, empresas multicomunales, empresas de gestión, contratos de colaboración empresarial (consorcios), entre otros, de modo que pueda establecerse alianzas estratégicas entre organizaciones de productores y exportadores, con beneficios para ambos.

\subsection{Eslabón de transformación}

\section{Cosecha y poscosecha}

La mayoría del café peruano es exportado como grano verde. Las semillas de café son extraídas del fruto o cerezo (por su semejanza con la cereza), luego se les retira la cáscara externa y la pulpa (material mucilaginoso que recubre las semillas), con lo cual se obtiene el café mote. Éste debe perder humedad hasta llegar a entre 10 y $12 \%$ de su peso para convertirse en el café pergamino (la semilla queda recubierta de una delgada lámina), que es el bien que transa el productor. En todo el proceso, la mayor parte de los caficultores sigue técnicas tradicionales, sin mayor preocupación por preservar la calidad del grano.

Las labores de beneficio hacen frente a una serie de obstáculos, principalmente porque coinciden con la época de lluvias. No hay una infraestructura física adecuada para el secado y es muy difícil transitar por los caminos rurales. En estas condiciones, el secado, almacenamiento y transporte del café propicia la formación

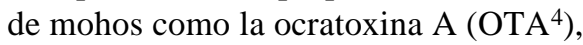

4. La OTA es una micotoxina derivada del metabolismo de hongos como Penicillium verrucosum y Aspergillus ochraceus que está clasi- 
con el consecuente deterioro de la calidad del café.

La mayoría de los productores no reciben orientación técnica, por lo que no cosechan ni benefician su café de manera apropiada; más bien, deterioran la calidad del producto. Al respecto, existe escasa bibliografía técnica accesible para los agricultores, tanto por el costo de la publicación como por la escasa instrucción formal que la mayoría ha recibido. Lo ideal sería poner en manos de los agricultores textos claros y sencillos, ilustrados y diagramados de modo que motiven la lectura y sean de utilidad para revertir la falta de conocimiento.

En entrevistas realizadas a los agricultores y autoridades de instituciones gubernamentales, como la Dirección General de Promoción Agraria del Minag (DGPA), se ha sabido de anteriores proyectos de capacitación que no han logrado mayor impacto porque no hubo un seguimiento permanente a los beneficiarios ni éstos contaron con los insumos necesarios. En buena cuenta, el agricultor no pudo llevar a la práctica lo aprendido.

Lo deseable es que el agricultor cuente con la guía de un ingeniero agrónomo especializado en cultivos orgánicos $\mathrm{y}$, por supuesto, en el manejo tecnificado del café, de modo que reciba capacitación directa durante las actividades de cosecha, mantenimiento y poscosecha de los cultivos. Además, el proceso de poscosecha requiere de inversión en equipos y en el

ficada como posible cancerígeno para el ser humano. Algunos países han implementado restricciones para el ingreso de los productos (incluido el café) cuyos niveles de OTA excedan los máximos permitidos. mantenimiento de éstos para asegurar la calidad física y «de taza» del producto.

\section{Transporte}

Como el producto es generalmente transportado a la costa como café pergamino, en el camino se van generando una serie de sobrecostos. Por un lado, la escasa infraestructura para su industrialización en la zona de origen vuelve al café más vulnerable a los cambios de humedad ambiental. Por otro lado, con frecuencia las vías de penetración son bloqueadas como medida de protesta por grupos con intereses específicos.

\section{Industrialización}

La industrialización se realiza mayormente en ciudades cercanas a los puertos principales: Paita y Callao. Sin embargo, en estas plantas de transformación la capacidad instalada está diseñada para trabajar con grandes volúmenes de café convencional, de modo que el café de especialidad, cuyos volúmenes son más pequeños, deben asumir nuevos sobrecostos.

Adicionalmente, muy pocas plantas cuentan con certificación sustentable o con procedimientos acordes con la preservación de la calidad, por lo que la creciente demanda corre el riesgo de saturar la oferta de los proveedores de procesamiento de café especial, lo que tiende a aumentar los precios del servicio.

Por otra parte, la experiencia en tostado del café es aún insuficiente. Actualmente, algunas empresas están incursionando en este proceso motivadas por el ingreso de compañías extranjeras especializadas, pero la mayoría del café todavía se exporta como grano verde. 
En cuanto al marco regulatorio, el procesamiento, almacenamiento, transporte y comercialización del café pergamino y verde están normados por 18 normas técnicas peruanas de café, dirigidas a mejorar la calidad del grano (Indecopi, 2001), mientras que los cafés especiales han merecido ya una primera norma técnica, con la cual se intenta brindar un marco de referencia para impulsar a los productores a incursionar en el mercado de alto precio (Indecopi, 2003).

\subsection{Eslabón de comercialización}

El 95\% del café peruano está orientado a la exportación. Sin embargo, problemas de transporte pueden convertirse en amenazas para las futuras exportaciones cafetaleras. Ricardo Huancaruna, director general de Perhusa, explicó que la falta de espacio en los barcos y al alza de los fletes están retrasando los embarques. Ocurre que las navieras prefieren llenar completamente sus bodegas en Chile y no tocar puertos peruanos, donde recogen carga en pequeños lotes; la capacidad exportadora del Perú es mucho menor que la del vecino del sur. De persistir esta situación, el país sufriría un perjuicio, pues entre julio y setiembre se concentran los mayores volúmenes de embarque. Ante limitaciones como la descrita, cabe preguntarse si el gobierno debe asumir el reto de promover empresas navieras nacionales (Aroma y Sabor, jul. 2004).

En el ámbito mundial, los tostadores y cafeterías especializadas compiten en el mercado de especialidad no sobre la base de precios, sino estableciendo una conexión personal con el consumidor y proporcionándole un ambiente de cierta exclusividad; se dirigen a quienes tienen gustos refinados y saben apreciar el sabor.
En cuanto al mercado interno, actualmente el país absorbe tan sólo 300 gramos anuales promedio por persona (Aroma y Sabor, may.-jun. 2004), en contraste con países desarrollados, como Estados Unidos o Finlandia, donde el consumo anual es de 4 kilos y 11,3 kilos, respectivamente, por persona (Castañeda, 2004). Además, en el Perú el mayor consumo corresponde a la modalidad de café soluble, donde se mezclan variedades arábica con robusta para abaratar los costos.

Cabe señalar que el poblador peruano no es consciente de la calidad del café que consume. Sin embargo, algunas empresas cafetaleras han empezado a comercializar internamente el café tostado y molido que ha sido reconocido en más de un evento de cafés especiales, y están logrando una creciente aceptación del público acostumbrado al café soluble.

\subsection{El marco institucional del sector caficultor peruano}

En una economía globalizada y de mercados abiertos el café peruano debe prepararse para competir como un producto de alta calidad e inocuidad. La normatividad legal para las exportaciones e importaciones deben respaldar esta meta, pero además es prioritario el fortalecimiento de la institucionalidad de todos los agentes que participan en el sector cafetalero.

Al respecto, un elemento decisivo es el Consejo Nacional del Café, ente representativo del sector cafetalero creado mediante Resolución Suprema n. ${ }^{\circ}$ 005-2002AG y encargado de identificar, analizar y proponer el marco legal y los lineamientos de política, para el corto, mediano y largo plazo en relación con el desarrollo 
de la actividad caficultora. Está integrado por la Junta Nacional de Café, la Cámara Peruana de Café y el Ministerio de Agricultura. Como primer paso, este consejo ha iniciado el diálogo entre los principales actores involucrados a fin de concentrar esfuerzos para ofertar un producto de calidad al mundo. Gracias a la concertación, se ha logrado difundir una buena imagen del café peruano en el exterior, eliminar los castigos que se venían aplicando en los precios de compra y participar en eventos internacionales, donde se ha logrado obtener premios de reconocimiento mundial.
Igualmente, el Ministerio de Agricultura, en particular la DGPA, está trabajando con grupos de productores para conocer su realidad y diseñar una estrategia de desarrollo global como parte del lanzamiento del Plan Estratégico del Café.

Como punto final, cabe señalar que en países como Costa Rica o Colombia el desarrollo de una marca propia para el café en el extranjero ha dependido de una iniciativa nacional, hecho que debe ser tomado en cuenta por las organizaciones peruanas.

\section{Referencias bibliográficas}

ASOCIACIÓN PERUANA DE CAFÉS ESPECIALES. 2004. In Peru... our gold grows on trees. Lima: Apecafé.

CÁMARA PERUANA DEL CAFÉ. 2002. [http://www.camcafeperu.com.pe/ cpc_index.htm].

- 2003. Noticias: Aprobación de la reducción del descuento al café Peruano en el New York Board Of Trade (NYBOT). [http://www.camcafeperu.com.pe/noticias _index.htm].

CASTAÑEDA, Enrique. 2000. $E l A B C$ del café: cultivando calidad. Lima: Tecnatrop.

2004. Bases potenciales: de la chacra cafetalera diversificada y amigable con el medio ambiente. Lima: Tecnatrop.

CENTRO DE COMERCIO INTERNACIONAL UNCTAD/GATT. 1992. Café: guía del exportador. Ginebra: CCI UNCTAD/ GATT.

\footnotetext{
-1996. Café: Guía del exportador. Suplemento. Ginebra: CCI UNCTAD/GATT.

-2002. Café: Guía del exportador. Ginebra: CCI UNCTAD/GATT.
}

CENTRO DE COMERCIO INTERNACIONAL UNCTAD/OMC. 2002. Café: guía del exportador. Ginebra: CCI. UNCTAD/ GATT. Capítulo 3: Mercados nicho, aspectos ambientales y sociales [http:// www.intracen.org/mds/sectors/coffee/ chap3spa.pdf] (12-10-2004).

COFFEE RESEARCH INSTITUTE. 2004. Green Coffee Classification Overview. [http://www.coffeeresearch.org/coffee/ classification.htm].

2004. New York Coffee Exchange Overview [http://www.coffeeresearch.org/ market/coffeemarket.htm].

2004. SCAA Green Coffee Classification [http://www.coffeeresearch.org/ coffee/scaaclass.htm]. 
- - Green Coffee Classification: Brazil / New York method [http://www. coffeeresearch.org/coffee/brazilclass.htm].

FAIRTRADE LABELLING ORGANIZATIONS INTERNATIONAL. 2004. Criterio genérico de Comercio Justo para pequeños agricultores de café [http:// www.fairtrade.net/pdf/sp/spanish/ Cafe\%20SP\%20Jun.04\%20.pdf].

GIOVANNUCCI, D. 2001. Encuesta sobre café sustentable en el mercado de especialidad de América del Norte

[ h t t p : //www.sc a a .org/pdf s / 2001_Cafe_Sustentable_NA.pdf].

INTERNATIONAL COFFEE ORGANIZATION. 2004. History. International Coffee Organization [http://www.ico.org/ history.asp] (4-12-04).

JAMAICAN BLUE MOUNTAIN COFFEE. [http://www.bluemountaincoffee.com/].

JUNTA NACIONAL DEL CAFÉ. [http:// www.cepes.org.pe/cendoc/Jnc\%20final/ 00principal/texto_quienes.htm].

JUNTA NACIONAL DEL CAFÉ y CENTRO PERUANO DE ESTUDIOS SOCIALES. 2003. Aroma y Sabor: Boletín Electrónico. Abr.-may., n. ${ }^{\circ} 17$

[http://www.cepes.org.pe/cendoc/cultivos/ cafe/2003/20030400/20030400.htm] (2210-2004).

- 2004. Aroma y Sabor: Boletín Electrónico. May.-Jun., n. ${ }^{\circ} 26$ [http://www. juntadelcafe.org.pe/cendoc/cultivos/cafe/ aromaysabor.htm] (22-10-2004).

2004. Aroma y Sabor: Boletín Electrónico. Jul., n. ${ }^{\circ} 27$ [http://www.juntadel cafe.org.pe/cendoc/cultivos/cafe/aromay sabor.htm] (22-10-2004).
MAXIMIXE. 2002. Riesgos de mercados: el turno de los cafés orgánicos y especiales. Lima: CASER.

PERÚ. INSTITUTO NACIONAL DE DEFENSA DEL CONSUMIDOR Y DE LA PROPIEDAD INTELECTUAL. 2001. Norma Técnica Peruana NTP 209.027: Café Verde. Requisitos. Lima. Indecopi.

2003. Norma Técnica Peruana NTP 209.311: Cafés Especiales. Requisitos. Lima. Indecopi.

PERÚ. INSTITUTO NACIONAL DE ESTADÍSTICA E INFORMÁTICA. 1994. III Censo Nacional Agropecuario. [http:// www.inei.gob.pe/BancoCuadros/bancua 06a.asp?PARAMETRO=03000000Nivel: Nacional].

PERÚ. MINISTERIO DE AGRICULTURA. 2004. Portal agrario: cadena productiva del café. [www.portalagrario.gob.pe/ dgpa_cad.htm].

2004. Café: producción. [http:// www.portalagrario.go.pe/cgi-bin/ op_comercial.cgi] (17-6-2004).

PERÚ. Café peruano obtiene medalla de oro en concurso mundial realizado en París. Nota de Prensa 302-04. Lima. 17-06-05 [http://www.rree.gob.pe/portal/ boletinInf.nsf/d900ab5823c15b6105256 bf40082b79b/70d1c791e3addc2505256 eb6007bd6eb?OpenDocument].

PERÚ. SUPERINTENDENCIA NACIONAL DE ADMINISTRACIÓN TRIBUTARIA. 2004. Portal de aduanas: Exportaciones de café del 2002 al 2004. [www.sunat.gob.pe].

RAINFOREST ALLIANCE. [http://www. rainforest-alliance.org/]. 
RIZZO, P. El café orgánico de las islas Galápagos. Proyecto SICA/MAG. Ecuador. [http://www.sica.gov.ec/agronegocios/ Biblioteca/Ing\%20Rizzo/puertos $\% 20 \& \% 20$ galapagos/cafe_organico.htm] (3-12-04).

\section{SMITHSONIAN MIGRATORY BIRD CEN-} TER. [http://nationalzoo.si.edu/Conserva tionandScience/MigratoryBirds/Coffee/ default.cfm].

THE CUP OF EXCELLENCE. [http://www. cupofexcellence.org/].

VIETO, J. 2004a. Cambios estructurales en el café. Centro de Inteligencia sobre Mercados Sostenibles. Exposición en el seminario «Café sostenible: situación y perspectivas de oferta y mercado». Lima, Prómpex, 7 dic. de 2004.

- 2004b. Panorama de las certificaciones sostenibles. Centro de Inteligencia sobre Mercados Sostenibles. Exposición en el seminario «Café sostenible: situación y perspectivas de oferta y mercado». Lima, Prómpex, 7 dic. de 2004.

2004c. Precios y premios del café sostenible y costos de certificaciones. Centro de Inteligencia sobre Mercados Sostenibles. Exposición en el seminario «Café sostenible: situación y perspectivas de oferta y mercado». Lima, Prómpex, 7 dic. de 2004.

VILLALOBOS, A. 2004a. Canales de comercialización del café sostenible. Centro de Inteligencia sobre Mercados Sostenibles. Exposición en el seminario «Café sostenible: situación y perspectivas de oferta y mercado». Lima, Prómpex, 7 dic. de 2004.

2004b Situación de la oferta latinoamericana de café sostenible: 2003-2004. Centro de Inteligencia sobre Mercados Sostenibles. Exposición en el seminario «Café sostenible: situación y perspectivas de oferta y mercado». Lima, Prómpex, 7 dic. de 2004.

2004c. Situación del mercado de cafés diferenciados. Centro de Inteligencia sobre Mercados Sostenibles. Exposición en el seminario «Café sostenible: situación y perspectivas de oferta y mercado». Lima, Prómpex, 7 dic. de 2004.

2004d. Tendencias del mercado de café sostenible. Centro de Inteligencia sobre Mercados Sostenibles. Exposición en el seminario «Café sostenible: situación y perspectivas de oferta y mercado». Lima, Prómpex, 7 dic. de 2004. 